\title{
Genetic Causes of Aortic Aneurysms Unlearning At Least Part of What the Textbooks Say
}

\author{
Helena Kuivaniemi, Gerard Tromp, and Darwin J. Prockop \\ Department of Biochemistry and Molecular Biology, Jefferson Institute of Molecular Medicine, \\ Jefferson Medical College, Thomas Jefferson University, Philadelphia, Pennsylvania 19107
}

"The most common cause of aortic aneurysms is atherosclerosis."-Harrison's Textbook of Medicine, 11 th ed. (1).

Two new developments indicate that the statements in standard textbooks about the causes of aortic aneurysms should be reexamined. They also have important implications for the treatment and management of patients and families with the disease.

One recent development was a series of careful studies of families of patients with aortic aneurysms. Rupture of aortic aneurysms accounts for $1-2 \%$ of deaths in industrialized countries $(2,3)$, but no attempts to define the family incidence of the disease were carried out until recently (Table I). Tilson and Seashore were among the first to report a relatively high familial incidence of the disease (4), and now several groups have confirmed their findings. In one of the most thorough studies, Bengtsson and co-workers (5) used ultrasound to examine the aortas of 87 asymptomatic brothers and sisters of 32 patients who had undergone surgery for abdominal aortic aneurysms. At the time they were examined, $29 \%$ of the brothers and $6 \%$ of the sisters had aortic aneurysms as defined by dilatations of $>2.9 \mathrm{~cm}$ at the level of the coeliac axis. A similar kind of study was carried out in the United States by Webster et al. (6) who carried out ultrasound screening of 103 first-degree relatives of 43 patients with an abdominal aortic aneurysm. In relatives who were $50 \mathrm{yr}$ or older, $13 \%$ of siblings were found to have previously undiagnosed abdominal aortic aneurysm. Similar values for the familial incidence of the disease were observed in several studies in which patients and families were interviewed but not examined further (7-12).

The reports from these several groups established that aortic aneurysms are familial, and, therefore, strongly suggested that they are caused by genetic defects. The relatively high incidence of affected members of families suggested that the disease is dominantly inherited but a recent statistical evaluation (13) supported recessive inheritance. The family studies did not contradict the general impression that the development of aneurysms is accelerated by atherosclerosis, hypertension, and other factors. In fact, the higher incidence among brothers than sisters of patients strongly suggested a secondary component such as atherosclerosis contributes to the disease. The results, however, strongly suggested that a genetic defect unrelated to any genetic defect causing atherosclerosis or hypertension is the underlying cause of most aortic aneurysms.

Received for publication 30 May 1991.

J. Clin. Invest.

(c) The American Society for Clinical Investigation, Inc.

$0021-9738 / 91 / 11 / 1441 / 04 \$ 2.00$

Volume 88, November 1991, 1441-1444
Of special interest is the observation that although most affected members of the families studied develop aneurysms only of the aorta, some also develop cerebral aneurysms (14). Therefore, the results raised the possibility that both aortic and cerebral aneurysms have a common genetic cause.

The second recent development came from analysis of collagen genes. Research over the past 10 years has demonstrated that mutations in either of the two structural genes for type I procollagen are the most common cause of osteogenesis imperfecta ("brittle bone disease"). Over $90 \%$ of patients with osteogenesis imperfecta have been shown to have mutations in the genes for type I procollagen and over 70 different mutations have been found in unrelated patients with the disease (15). With a few exceptions, the mutations cause synthesis of structurally abnormal but partially functional pro $\alpha$ chains of type I procollagen that either interfere with the normal assembly of the type I procollagen molecule or interfere with the assembly of collagen fibrils by normal type I collagen synthesized by the same fibroblasts from heterozygous probands. The disastrous effects of the mutations, therefore, are largely explained by the fact that fibers of type I collagen are a major source of the structural strength of bone. The mutations either decrease the amount of type I collagen fiber synthesized or generate abnormal fibrils. In parallel experiments, several patients with severe chondrodysplasias were found to have similar mutations in the gene for type II procollagen, the precursor of type II collagen that is a major source of the strength of cartilage (15). Also, mutations in the gene for type III procollagen were found in a series of patients (16-23) with the type IV variant of EhlersDanlos syndrome (24-27) that is characterized by sudden death from rupture of the aorta and other hollow organs such as the intestine. Again, the consequences of the mutations are largely explained by the fact that the tensile strength of large blood vessels largely depends on fibrils of type III collagen that are very similar in structure and function to the fibrils of type I collagen found in bone and the fibrils of type II collagen found in cartilage. More recently, evidence suggesting a mutation in type I procollagen was reported in two unrelated families with osteopenia and a mutation in the pro $\alpha 2(\mathrm{I})$ gene was defined in a woman who presented with postmenopausal osteoporosis (15). Also, linkage studies suggested mutations in the gene for type II procollagen in two families with osteoarthritis and a mutation in the type II procollagen gene was found in affected members of one large family with osteoarthritis associated with a chondrodysplasia (15).

For these and related reasons, we initiated a series of experiments to test the hypothesis that mutations in the gene for type III procollagen might be a cause of aortic aneurysms in families without any other evidence of genetic disease. A mutation in the type III procollagen gene was found in a man who expired 
Table I. Patients Surveyed

\begin{tabular}{|c|c|c|c|c|c|}
\hline \multirow[b]{2}{*}{ Survey method } & \multirow{2}{*}{$\begin{array}{c}\text { Total } \\
\text { number }\end{array}$} & \multirow{2}{*}{$\begin{array}{l}\text { Patients with } \\
\text { one or more } \\
\text { affected family } \\
\text { member }\end{array}$} & \multicolumn{2}{|c|}{$\begin{array}{l}\text { Incidence in affected } \\
\text { families }\end{array}$} & \multirow[b]{2}{*}{ Reference } \\
\hline & & & Siblings & All relatives & \\
\hline & & $\%$ & $\%$ & & \\
\hline Sonography & 32 & 34 & $15^{*}$ & & 5 \\
\hline Sonography & 43 & 30 & $13^{\ddagger}$ & $7^{8}$ & 6 \\
\hline Interviews & 542 & 15 & & & 7 \\
\hline Interviews & 250 & 19 & & & 8 \\
\hline Interviews & 305 & 11 & & & 9 \\
\hline Interviews & 87 & 18 & & & 12 \\
\hline Interviews & 666 & 6 & & & 11 \\
\hline Interviews & 56 & 36 & $7^{11}$ & $8^{11}$ & 10 \\
\hline
\end{tabular}

* Asymptomatic aortic dilatations of $>2.9 \mathrm{~cm}$ were found in $29 \%$ of 35 brothers, $6 \%$ of 52 sisters. Average age of the brothers and sisters was $63 \mathrm{yr}$.

\# Aortic dilatations were found in $13 \%$ of 54 siblings over age of $50 \mathrm{yr}$.

Aortic dilatations detected in $7 \%$ of 103 relatives (parents, siblings, and children) over the age of $40 \mathrm{yr}$.

" $7 \%$ of 192 brothers and sisters, and $8 \%$ of 320 first degree relatives.

at the age of 34 from diffuse bleeding of the aorta (28). The man had a history of easy bruisability and bleeding, but none of the dramatic skin changes usually associated with type IV EhlersDanlos syndrome such as ecchymoses, scarring, and heavy pigmentation. He, therefore, probably represented phenotypic overlap between Ehlers-Danlos syndrome type IV and familial aneurysms. Subsequently, we found a mutation in the type III procollagen gene (29) in a 37-yr-old woman who was in excellent health but was concerned because of a strong family history of sudden death from ruptured aortic aneurysms (Fig. 1). The mutation converted the codon for glycine at amino acid position $\alpha 1-619$ to a codon for arginine and decreased the thermal stability of fragments from type III procollagen synthesized by her cultured skin fibroblasts. The same mutation in the type III procollagen gene was found in surgical specimens of the aorta from her aunt who died in 1986 with multiple aneurysms of the aorta and related arteries at the age of 55. Also, the same mutation was found in tissue from a microscopic slide from the aorta of her mother who died of a ruptured aortic aneurysm at the age of 34 in 1960 (Fig. 2). Assays with the polymerase chain reaction on samples of saliva from several members of the family demonstrated that five family members inherited the mutation (29). Periodic ultrasound examination has recently demonstrated a developing aortic aneurysm in one of the five individuals.

The family studies and gene analyses provide several conclusions about aortic aneurysms. One conclusion is that they are frequently familial and, therefore, probably genetic in these families. The other conclusion is that mutations in the gene for type III procollagen, the precursor of a major structural protein of the aorta, are a cause of aortic aneurysms in some families and may well be in many others. To date, the type III procollagen gene has been analyzed only in less than 20 families with aortic aneurysms and the analyses that have been carried out are incomplete. Therefore, it is clear that more gene analyses must be performed in such families on the gene for type III procollagen, as well as on genes for other structural proteins that may contribute to the strength of the aorta.

These conclusions have very direct implications for the management of patients and families with aortic aneurysms. Early surgical treatment of the disease is clearly of great benefit. Numerous reports have demonstrated that individuals who undergo elective surgery for the repair of aortic aneurysms have a survival rate of $>90 \%$, and many apparently have a normal life span $(30,31)$. In contrast, the survival rate among individuals who begin to hemorrhage can be as low as $10 \%$ (11). Also, the hospitalization costs for individuals who undergo elective repair of aortic aneurysms is about one-tenth the cost of surgical repair in individuals whose aneurysms have begun to bleed. For these reasons, a DNA diagnostic test for mutations causing aortic aneurysms is clearly of benefit to families in whom such mutations can be identified.

At the moment, there are several limitations to DNA diagnostic tests for aortic aneurysms. The gene for type III procollagen is large and contains 52 exons, any one of which could have a mutation that causes aneurysms. Therefore, extensive gene analyses are required to identify the mutation in a new family. Fortunately, improved technologies have reduced the time to sequence a large gene such as the type III procollagen gene from $>2$ yr to less than $\sim 1 \mathrm{wk}(32-38)$. The techniques are continually being improved and, therefore, it is reasonable to expect that in time such analyses will be commonly available to clinicians and to families. Once the mutation in a type III procollagen gene causing aneurysms in a family is defined, it is relatively easy to screen DNA from saliva and other sources from

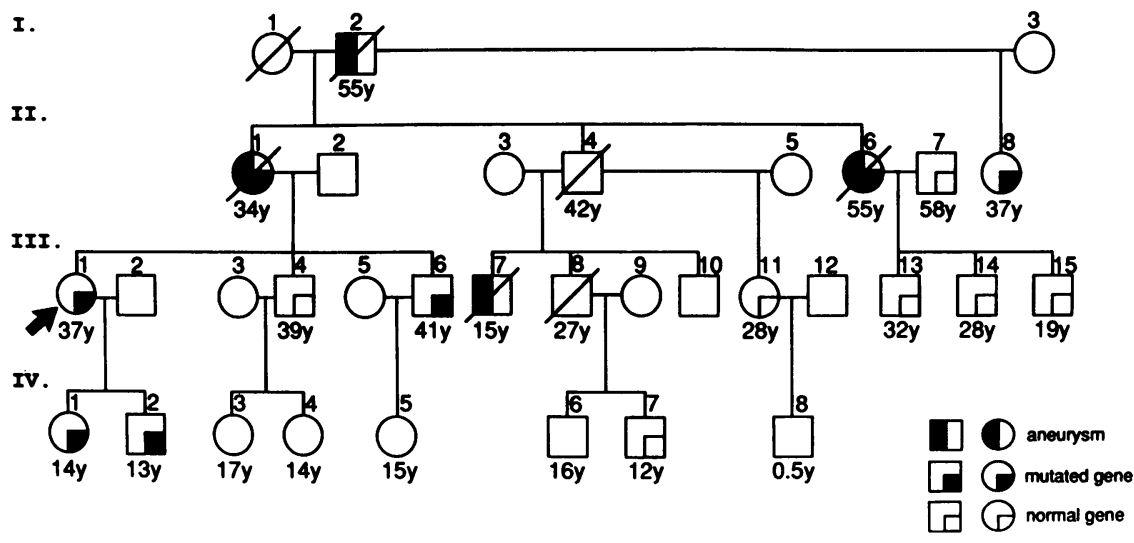

Figure 1. Family with aortic aneurysms. Diagonal line indicates members who died at the ages indicated. Arrow indicates the index case, a 37-yr-old captain in the United States Air Force in excellent health. She had a substitution of arginine for glycine $\alpha 1-619$ in her gene for type III procollagen. The same mutation was found in tissue from microscopic slides from her mother (II-1) who died in 1960 of an aortic aneurysm and her aunt (II-6) who died of an aortic aneurysm in 1986. DNA tests on saliva from surviving members of the family indicated that five had the mutation and five did not. One of the individuals with the mutation was recently found to have an early aortic aneurysm by routine sonography. Reproduced with permission (29). 

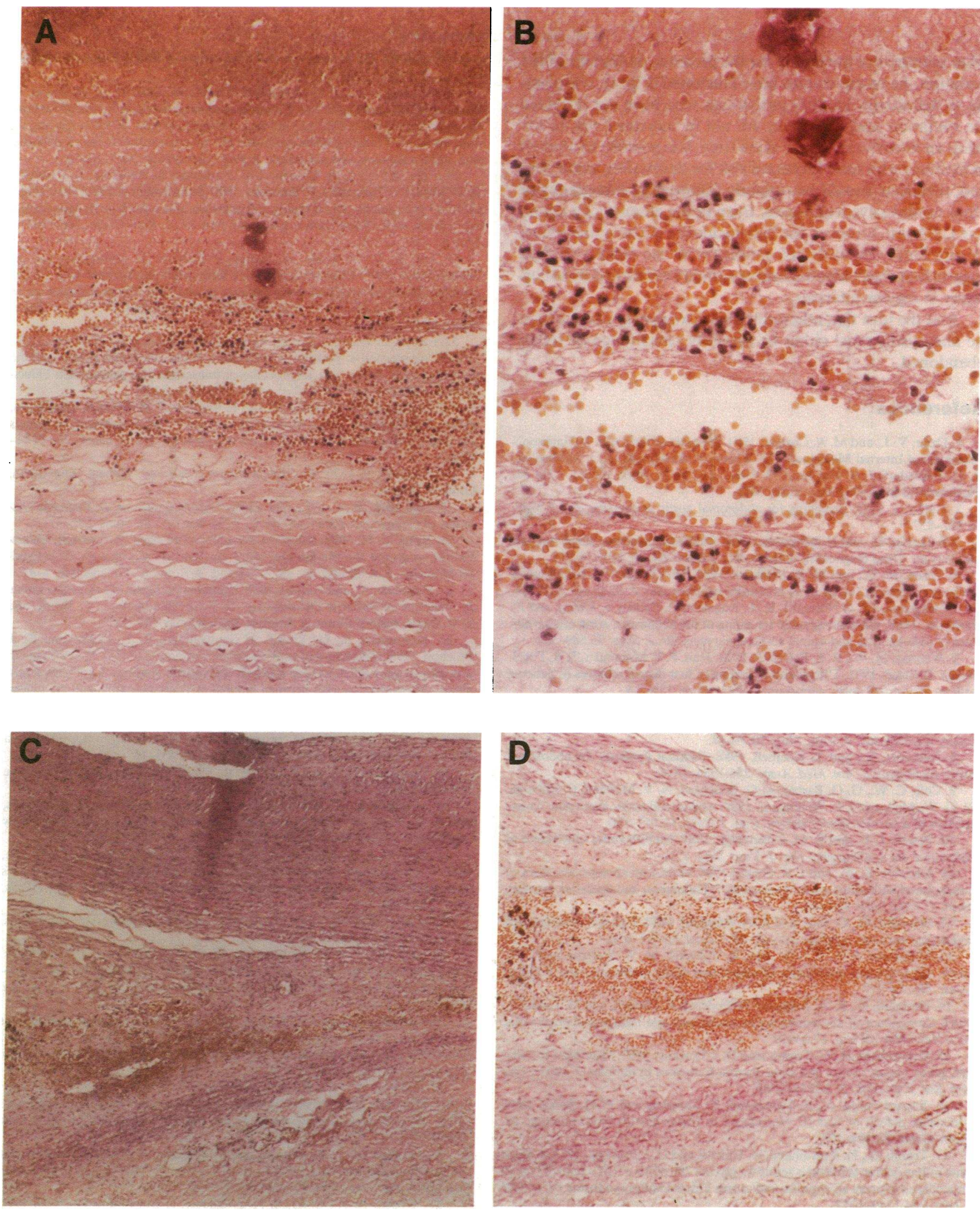

Figure 2. Photomicrographs from one of the three slides available from the aortic aneurysm found in the mother (II-1) of the index case. As indicated in text, one of the slides was used for the polymerase chain reaction to demonstrate the presence of the mutation in the type III procollagen gene. The specimen was stained with hematoxylineosin. $(A)$ Section through the aortic aneurysm. A recent blood clot is attached to the intima (top). The intima appears amorphous and the media (bottom) is dissected. Blood is present in the center of the medial tissue. Magnification, 134. (B) Higher magnification of the dissection in the media. Remnants of the media are shown on either side of the dissection. Amorphous structures on the top are probably artifacts in the preparation. Magnification, 355. (C) Section through another part of the aorta. The intima $(t o p)$ is well organized but there is thickening of the media and bleeding into the thickened media (bottom left). The splits in the intima and media are probably artifacts from preparation. Magnification, 57. $(D)$ Enlargement of $C$. There is some revascularization of the thickened media. Magnification, 90 . 
other members of the family for the presence or absence of the mutation. As recent studies have illustrated (Fig. 1), it is possible to definitively identify individuals who have not inherited the mutation and, therefore, are not at increased risk to develop an aneurysms. At the same time, it is possible to identify individuals who have increased risk for developing aneurysms and, therefore, should be regularly followed by sonography or other noninvasive techniques. Even in the absence of a definitive DNA test, however, the high incidence of aortic aneurysms among family members of patients with the disease strongly suggest that direct blood relatives should be followed by sonography at regular intervals.

And the idea that atherosclerosis is a primary cause of aortic aneurysms must either be carefully reexamined or totally abandoned.

\section{References}

1. Dzau, V. J., and M. A. Creager. 1991. Diseases of the aorta. In Harrison's Principals of Internal Medicine. J. D. Wilson, E. Braunwald, K. J. Isselbacher, R. G. Petersdorf, J. B. Martin, A. S. Fauci, and R. K. Root, editors. 12th ed. McGraw-Hill Book Co., New York. 1016.

2. Collin, J. 1985. Screening for abdominal aortic aneurysms. Br. J. Surg. 72:851-852.

3. Bergqvist, D., and H. Bengtsson. 1986. Ökat antal patienter dör av bukaortaaneurysm. Ökad diagnostisk skärpa krävs. Lakar-tidn. 83:3010-3012.

4. Tilson, M. D., and M. R. Seashore. 1984. Fifty families with abdominal aortic aneurysms in two or more first-order relatives. Am. J. Surg. 147:551-553.

5. Bengtsson, H., O Norrgård, K. A. Ängquist, O. Ekberg, L. Öberg, and D. Bergqvist. 1989. Ultrasonographic screening of the abdominal aorta among siblings of patients with abdominal aortic aneurysms. Br. J. Surg. 76:589-591.

6. Webster, M. W., R. E. Ferrell, P. L. St. Jean, P. P. Majumder, S. R. Fogel, and D. L. Steed. 1991. Ultrasound screening of first-degree relatives of patients with an abdominal aortic aneurysm. J. Vasc. Surg. 13:9-14.

7. Darling III, R. C., C. D. Brewster, R. C. Darling, G. M. LaMuraglia, A. C. Moncure, R. P. Cambria, and W. M. Abbott. 1989. Are familial abdominal aortic aneurysms different? J. Vasc. Surg. 10:39-43.

8. Johansen, K., and T. Koepsell. 1986. Familial tendency for abdominal aortic aneurysms. J. Am. Med. Assoc. 256:1934-1936.

9. Cole, C. W., G. G. Barber, A. G. Bouchard, N. V. McPhail, C. Roberge, W. G. Waddell, and J. L. Wellington. 1989. Abdominal aortic aneurysm: consequences of a positive family history. Can. J. Surg. 32:117-120.

10. Powell, J. T., and R. M. Greenhalgh. 1987. Multifactorial inheritance of abdominal aortic aneurysm. Eur. J. Vasc. Surg. 1:29-31.

11. Johnston, K. W., and T. K. Scobie. 1988. Multicenter prospective study of nonruptured abdominal aortic aneurysms. I. Population and operative management. J. Vasc. Surg. 7:69-81.

12. Norrgård, Ö., O. Rais, and K. A. Ängquist. 1984. Familial occurrence of abdominal aortic aneurysms. Surgery (St. Louis). 95:651-656.

13. Majumder, P. P., P. L. St. Jean, R. E. Ferrell, M. W. Webster, and D. L. Steed. 1991. On the inheritance of abdominal aortic aneurysm. Am. J. Hum. Genet. 48:164-170.

14. Norrgård, Ö., K.-A. Ängqvist, H. Fodstad, Ả. Forssell, and M. Lindberg. 1987. Coexistence of abdominal aortic aneurysms and intracranial aneurysms. Acta Neurochir. (Wien). 87:34-39.

15. Kuivaniemi, H., G. Tromp, and D. J. Prockop. 1991. Mutations in collagen genes: causes of rare and some common diseases in humans. FASEB (Fed. Am. Soc. Exp. Biol.) J. 5:2052-2060.

16. Superti-Furga, A., B. Steinmann, F. Ramirez, and P. H. Byers. 1989. Molecular defects of type III procollagen in Ehlers-Danlos syndrome type IV. Hum. Genet. 82:104-108.

17. Tromp, G., H. Kuivaniemi, H. Shikata, and D. J. Prockop. 1989. A single base mutation that substitutes serine for glycine 790 of the $\alpha$ l(III) chain of type III procollagen exposes an arginine and causes Ehlers-Danlos syndrome IV. J. Biol. Chem. 264:1349-1352.

18. Tromp, G., H. Kuivaniemi, C. Stolle, F. M. Pope, and D. J. Prockop. 1989. Single base mutation in the type III procollagen gene that converts the codon for glycine 883 to aspartate in a mild variant of Ehlers-Danlos syndrome IV. J. Biol. Chem. 264:19313-19317.

19. Kuivaniemi, H., S. Kontusaari, G. Tromp, M. Zhao, C. Sabol, and D. J. Prockop. 1990. Identical $\mathrm{G}^{+1}$ to A mutations in three different introns of the type III procollagen gene (COL3A1) produce different patterns of RNA splicing in three variants of Ehlers-Danlos syndrome IV. An explanation for exon skipping with some mutations and not others. J. Biol. Chem. 265:12067-12074.

20. Cole, W. G., A. A. Chiodo, S. R. Lamande, R. Janeczko, F. Ramirez, H. H. Dahl, D. Chan, and J. F. Bateman. 1990. Substitution at a splice site in the COL3A1 gene causes exon skipping and generates abnormal type III procollagen in a patient with Ehlers-Danlos syndrome type IV. J. Biol. Chem. 265:1707017077.

21. Lee, B., M. D'Alessio, H. Vissing, F. Ramirez, B. Steinmann, and A. Superti-Furga. 1991. Characterization of a large deletion associated with a polymorphic block of repeated dinucleotides in the type III procollagen gene (COL3A1) of a patient with Ehlers-Danlos syndrome type IV. Am. J. Hum. Genet. 48:511-517.

22. Lee, B., E. Vitale, A. Superti-Furga, B. Steinmann, and F. Ramirez. 1991. $\mathrm{G}$ to $\mathrm{T}$ transversion at position +5 of a splice donor site causes skipping of the preceding exon in the type III procollagen transcripts of a patient with EhlersDanlos syndrome type IV. J. Biol. Chem. 266:5256-5259.

23. Vissing, H., M. D'Alessio, B. Lee, F. Ramirez, P. H. Byers, B. Steinmann and A. Superti-Furga. 1991. Multi-exon deletion in the procollagen III gene is associated with mild Ehlers-Danlos syndrome type IV. J. Biol. Chem. 266:52445248.

24. Beighton, P. 1970. The Ehlers-Danlos Syndrome. William Heinemann, London. 194 pp.

25. McKusick, V. A. 1972. The Ehlers-Danlos syndrome. In Heritable Disorders of Connective Tissue. 4th ed. C. V. Mosby Co., St. Louis. 292-371.

26. Byers, P. H. 1983. Inherited disorders of collagen biosynthesis: EhlersDanlos syndrome, the Marfan syndrome, and osteogenesis imperfecta. In Clinical Medicine. J. A. Spittel, Jr., editor. Harper \& Row Co., Philadelphia. 1-41.

27. Shamban, A., and J. Uitto. 1989. Hereditary diseases of connective tissue. In Textbook of Pediatric Dermatology. R. Ruiz-Maldonado, L. C. Parish, and J. M. Beare, editors. Grune \& Stratton, Philadelphia. 117-141.

28. Kontusaari, S., G. Tromp, H. Kuivaniemi, R. L. Ladda, and D. J. Prockop. 1990. Inheritance of an RNA splicing mutation $\left(\mathrm{G}^{+1}\right.$ Ivs20 $)$ in the type III procollagen gene (COL3A1) in a family with aortic aneurysms and easy bruisability. Phenotypic overlap between familial arterial aneurysms and the EhlersDanlos syndrome type IV. Am. J. Hum. Genet. 47:112-120.

29. Kontusaari, S., G. Tromp, H. Kuivaniemi, A. M. Romanic, and D. J. Prockop. 1990. A mutation in the gene for type III procollagen (COL3A1) in a family with aortic aneurysms. J. Clin. Invest. 86:1465-1473.

30. Thomas, P. R. S., and R. D. Stewart. 1988. Mortality of abdominal aortic aneurysm. Br. J. Surg. 75:733-736.

31. Johansen, K., T. R. Kohler, S. C. Nicholls, R. E. Zierler, A. W. Clowes, and A. Kazmers. 1991. Ruptured abdominal aortic aneurysm: the Harborview experience. J. Vasc. Surg. 13:240-247.

32. Saiki, R. K., S. Scharf, F. Faloona, K. B. Mullis, G. T. Horn, H. A. Erlich, and N. Arnheim. 1985. Enzymatic amplification of $\beta$-globin genomic sequences and restriction site analysis for diagnosis of sickle cell anemia. Science (Wash. DC). 230:1350-1354.

33. Cotton, R. G. H. 1989. Detection of single base changes in nucleic acids. Biochem. J. 263:1-10.

34. Gibbs, R. A., P.-N. Nguyen, L. J. McBride, S. M. Koepf, and T. Caskey. 1989. Identification of mutations leading to the Lesch-Nyhan syndrome by automated direct DNA sequencing of in vitro amplified cDNA. Proc. Natl. Acad. Sci. USA. 86:1919-1923.

35. Ganguly, A., and D. J. Prockop. 1990. Detection of single-base mutations by reaction of DNA heteroduplexes with a water-soluble carbodiimide followed by primer extension: application to products from the polymerase chain reaction. Nucleic Acids Res. 18:3933-3939.

36. Gibbs, R. A., P.-N. Nguyen, A. Edwards, A. B. Civitello, and C. T. Caskey. 1990. Multiplex DNA deletion detection and exon sequencing of the hypoxanthine phosphoribosyltransferase gene in Lesch-Nyhan families. Genomics. 7:235-244.

37. Grompe, M., D. M. Munzny, and C. T. Caskey. 1989. Scanning detection of mutations in human ornithine transcarbamoylase by chemical mismatch cleavage. Proc. Natl. Acad. Sci. USA. 86:5888-5892.

38. Wilson, R. K., C. Chen, N. Avdalovic, J. Burns, and L. Hood. 1990. Development of an automated procedure for fluorescent DNA sequencing. Genomics. 7:626-634. 